\title{
O ensino projetual em Design no contexto da cibercultura a partir de uma ferramenta digital
}

\author{
La enseñanza proyecta en diseño en el contexto de la cibercultura a partir \\ de una herramienta digital
}

Teaching of Design in the cyberculture context using a digital tool

\author{
Jéssica Rodrigues Esteves ${ }^{1}$ \\ Renan Humberto Lunardello Fonseca ${ }^{2}$
}

\begin{abstract}
Resumo
O ensino de disciplinas projetuais em Design é focado no desenvolvimento de atividades práticas que exigem acompanhamento semanal dos docentes. Este artigo tem como objetivo relatar uma experiência docente, realizada com os alunos do oitavo semestre do Curso Técnico Integrado em Comunicação Visual do Instituto Federal Sulrio-grandense, no que tange à utilização de ferramentas digitais como estratégia pedagógica para o ensino da disciplina de Projeto Digital. A experiência evidenciou que o uso do Trello, um sistema de quadro virtual utilizado para gerenciamento de tarefas que seguem o método Kanban, auxiliou no ensino e aprendizagem de conteúdos, permitindo que docentes e discentes pudessem se comunicar, compartilhar materiais, organizar atividades e datas de entrega. Assim, o artigo discute o contexto da cibercultura através do uso de uma ferramenta digital para mediação pedagógica no ensino de disciplinas de projetos. A fim de problematizar o uso da ferramenta, é apresentado o resultado de um questionário qualitativo aplicado aos alunos, onde foram problematizados aspectos positivos e negativos quanto à utilização da plataforma como ferramenta pedagógica.
\end{abstract}

Palavras-Chave: Cibercultura; Ensino técnico; Educação e tecnologias; Prática pedagógica.

\section{Resumen}

La enseñanza de disciplinas proyectivas en Diseño se enfoca en el desarrollo de actividades prácticas que exigen seguimiento semanal de los docentes. Este artículo tiene como objetivo relatar una experiencia docente, realizada con los alumnos del octavo semestre del Curso Técnico Integrado en Comunicación Visual del Instituto Federal Sur-rio-grandense, en lo que se refiere a la utilización de herramientas digitales como estrategia pedagógica para la enseñanza de la disciplina de la disciplina Diseño Digital. La experiencia evidenció que el uso del Trello, un sistema de cuadro virtual utilizado para la gestión de tareas que siguen el método Kanban, ayudó en la enseñanza y aprendizaje de contenidos, permitiendo que docentes y discentes pudieran comunicarse, compartir materiales, organizar actividades y fechas de trabajo entrega. Así, el artículo discute el contexto de la cibercultura a través del uso de una herramienta digital para mediación pedagógica en la enseñanza de disciplinas de proyectos. A fin de problematizar el uso de la herramienta, se presenta el resultado de un cuestionario cualitativo aplicado a los alumnos, donde fueron problematizados aspectos positivos y negativos en cuanto a la utilización de la plataforma como herramienta pedagógica.

Palabras clave: Cibercultura; Educación técnica; Educación y tecnologías; Práctica pedagógica.

\begin{abstract}
The teaching of design disciplines is focused on the development of practical activities that require weekly followup of teachers. This article aims to report on a teaching experience, carried out with the students of the eighth semester of the Integrated Technical Course in Visual Communication of the Instituto Federal Sul-rio-grandense, regarding the use of digital tools as a pedagogical strategy for teaching a one discipline of Digital Design.
\end{abstract}

\footnotetext{
${ }^{1}$ Mestranda em Educação e Tecnologia; Instituto Federal Sul-rio-grandense - IFSul; Pelotas, RS, Brasil; jessica.rodrigues.esteves@gmail.com

${ }^{2}$ Mestre em Artes Visuais; Universidade Federal de Pelotas - UFPel; Pelotas, RS, Brasil; renanhlf@ gmail.com
} 
Experience has shown that the use of Trello, a virtual framework system used to manage tasks that follow the Kanban method, has aided content teaching and learning, allowing teachers and students to communicate, share materials, organize activities and delivery dates. Thus, the article discusses the context of cyberculture through the use of a digital tool for pedagogical mediation in the teaching of project disciplines. In order to problematize the use of the tool, the results of a qualitative questionnaire applied to the students were presented, where positive and negative aspects were discussed regarding the use of the platform as a pedagogical tool.

Keywords: Cyberculture; Technical education; Education and technologies; Pedagogical practice.

\section{Introdução}

A disseminação das novas tecnologias de Informação e Comunicação (TICs), propiciadas pela popularização da Internet, provocam impactos significativos na educação, alterando as relações de ensino e aprendizagem. Esta pesquisa trata-se de um relato de experiência que tem como objetivo discutir o uso de ferramentas digitais no ensino de disciplinas projetuais, partindo de uma experiência de ensino realizada na disciplina de Projeto Digital, pertencente ao oitavo semestre letivo do curso de Comunicação Visual do Instituto Federal Sul-rio-grandense (IFSul), Campus Pelotas, no primeiro semestre de 2018.

Esta experiência pedagógica ocorreu quando os pesquisadores atuaram como professores substitutos no IFSul, atuando em etapas distintas com a mesma turma na disciplina de Projeto Digital ao longo do oitavo semestre de 2018: um dos pesquisadores atuou nos primeiro três meses da disciplina - dado o fim de contrato - e o outro nos meses restantes até o término do semestre. Neste aspecto, evidenciou-se que o uso de uma ferramenta digital para organização das atividades docentes ajudou a compreensão do novo professor quanto aos trabalhos já desenvolvidos.

A disciplina de Projeto Digital, de acordo com a ementa, tem como objetivos: a) promover a discussão a respeito de diferentes tecnologias digitais (suportes) e linguagens a partir do ponto de vista da comunicação visual; b) discutir os conceitos de interface, interação e usabilidade; c) possibilitar ao estudante a oportunidade de experimentar processos de design digital voltados ao design digital; e d) promover a oportunidade de aplicação de conceitos do design em projetos de design digital. Além dos aspectos evidenciados nos objetivos, é importante ressaltar que a disciplina está relacionada a um projeto interdisciplinar de conclusão de curso, envolvendo as disciplinas de Projeto de Identidade Visual, Projeto Editorial e Ilustração; possibilitando que os alunos tenham a oportunidade de desenvolver um projeto completo de Comunicação Visual.

O ensino de uma disciplina projetual na área de Design envolve um acompanhamento semanal por parte dos professores, que precisam orientar os alunos para o desenvolvimento do trabalho. Ao observar esta situação, percebeu-se que o uso de uma ferramenta digital poderia 
facilitar o acompanhamento e desenvolvimento dos projetos, facilitando a comunicação entre docentes e discentes. Dentre as ferramentas gratuitas disponíveis, optou-se por utilizar o Trello, uma ferramenta utilizada para gerenciamento de projetos em quadros e listas. A opção por esta ferramenta deu-se devido à gratuidade, facilidade de utilização e disponibilidade de recursos. Diferente de Ambientes Virtuais de Aprendizagem (AVAs) tradicionais, como o Moodle (http://moodle.ifsul.edu.br/pelotas/) e o Q-Acadêmico (http://qacademico.ifsul.edu.br/), que possuem interfaces gráficas mais rígidas e inflexíveis, o Trello possui uma interface fluída e personalizável, tendo um aspecto geral mais amigável. Estes aspectos foram substanciais para a organização do quadro da disciplina de Projeto Digital, a partir das necessidades específicas do projeto.

Ao fim do semestre, foi enviado um questionário online para avaliar a percepção dos alunos sobre a utilização do Trello. A partir do questionário, foi possível elencar aspectos positivos e negativos da experiência e identificar a necessidade em se construir uma proposta didático-pedagógica para auxiliar professores e docentes na criação de quadros e listas no Trello.

\section{A cibercultura no contexto da educação}

É fato que as tecnologias da informação e comunicação (TICs) estão cada vez mais presentes no nosso dia-a-dia. De acordo com a última pesquisa do IBGE (2016), os brasileiros conectados à Internet somam 64,7\% de toda a população. Logo, é importante que as TICs sejam utilizadas também no ambiente educacional, tendo em vista que as novas gerações são nativas digitais, ou seja, cresceram imersas no ciberespaço. De acordo com Prensky (2001), estes alunos se relacionam com a tecnologia de forma diferente que as gerações anteriores.

A evolução e propagação das TICs foi propiciada pela cibercultura, conceito que remonta a uma corrente filosófica abordada por autores como Lévy (2005) e Lemos (2013), sendo uma evolução das tecnologias informacionais e comunicacionais que se sobrepuseram aos meios de comunicação em massa como, por exemplo, o rádio e a TV. De acordo com Lévy (2005), a maior diferença entre "cultura" e "cibercultura" é que a segunda é movida por pessoas que estão conectadas a uma rede de computadores, ou seja, existe uma troca de informações mundial entre as comunidades.

Com o advento do computador e da Internet, foram criados novos espaços de comunicação, de troca e de convívio social jamais presenciados em mídias tradicionais. Assim, essas novas formas de troca, de se comunicar via rede, são transformadas diariamente no ciberespaço dando origem a novas maneiras de interagir. Essas relações são naturais para 
estudantes nativos digitais e podem ser utilizadas em um ambiente educacional, tornando o aluno um sujeito ativo no processo de ensino e aprendizagem. Tônus (2008, p. 229) afirma que:

Ao pensarmos no processo de educação, inevitavelmente, entra em jogo a comunicação, não somente porque vivemos em uma sociedade midiática, mas porque a educação depende da comunicação para se concretizar [...] Com o avanço cada vez mais rápido das tecnologias da informação e da comunicação (TICs), o docente precisa aprender a lidar com elas, tanto para seu aprimoramento, como no caso de cursos e conferências, entre outras atividades, quanto para empregá-las como ferramentas educativas[...] (TÔNUS, 2008, p.229)

Tônus (2008) expressa a necessidade do docente manter-se atualizado e aberto a novas TICs, a fim de propor novas experiências pedagógicas no ambiente escolar. Cientes do desafio em ministrar uma disciplina projetual para o curso de Comunicação Visual, os autores buscaram uma ferramenta flexível e que fosse adaptável às necessidades dos alunos. O Trello, uma ferramenta para gestão e organização de projetos, já havia sido utilizado por outros professores dos cursos de Design do IFSul, por isso, resolveu-se utilizar a mesma ferramenta a fim de verificar seus aspectos positivos e negativos para o ensino de disciplinas projetuais.

\section{Apresentação do Trello e suas potencialidades pedagógicas}

Ao analisar a melhor forma de integrar métodos pedagógicos com o uso do ciberespaço e cibercultura para que os estudantes nativos digitais consigam aprender de maneira mais eficiente, optou-se por trabalhar com a ferramenta digital Trello. De acordo com as informações presentes no site oficial (https://trello.com/), o Trello é uma “maneira gratuita, flexível e visual de organizar tudo, com quem quiser". A ferramenta tem o objetivo de eliminar e-mails desnecessários e planilhas desatualizadas, elementos constantes na gestão de projetos, permitindo que o usuário possa visualizar todas as informações em um só lugar.

O Trello utiliza o método Kanban - palavra de origem japonesa que significa literalmente "cartão" - desenvolvido pela empresa Toyota devido a necessidade de manter a eficácia no funcionamento do sistema de produção em série. O método consiste na organização de cartões ou post-its em uma tela ou lousa para indicar o andamento dos fluxos de produção da empresa, conforme Figura 1. 


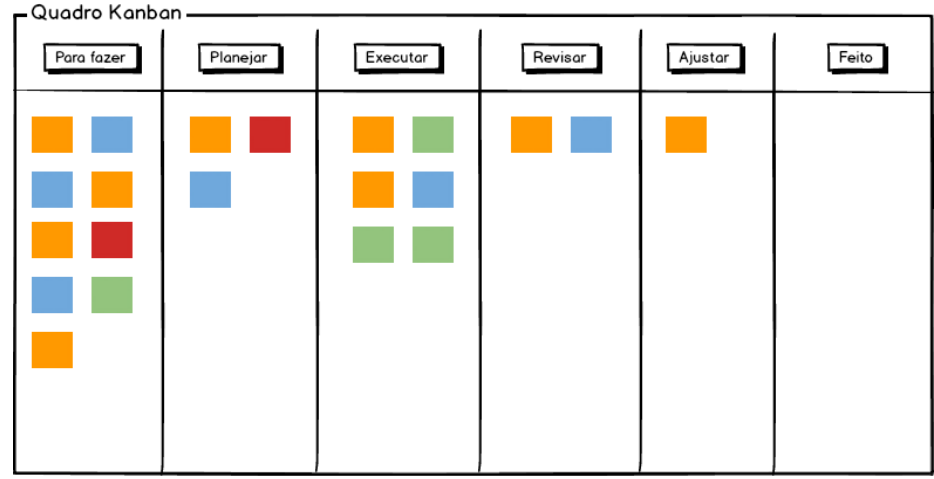

Figura 1 - Quadro do método Kanban.

Fonte: Diferencial TI. Disponível em: <https://blog.diferencialti.com.br/kanban-05-passos-para-comecar/quadrokanban//>. Acesso em 10 jan. 2019.

O e-Kanban é uma versão para a Internet do Kanban, substituindo a organização manual pela digital. Logo, no e-Kanban os cartões são organizados através de um software de gestão e podem ser consultados à distância por vários usuários ao mesmo tempo, evitando-se a perda e extravio de cartões. No Trello, os projetos são representados por quadros e as tarefas organizadas através de listas e cartões; itens que podem pertencer a um time ou não. Um quadro do Trello é uma tela em branco, que deve ser organizada pelo usuário de acordo com o seu objetivo, como mostra a Figura 1. Para explicar o funcionamento de quadros, listas e cartões foi criado um quadro fictício intitulado "Projeto Digital" - nome da disciplina para a qual a ferramenta foi utilizada. É importante ressaltar que todas as informações foram adicionadas pelos autores, tendo em vista que o Trello não possui nenhuma organização pré-definida.

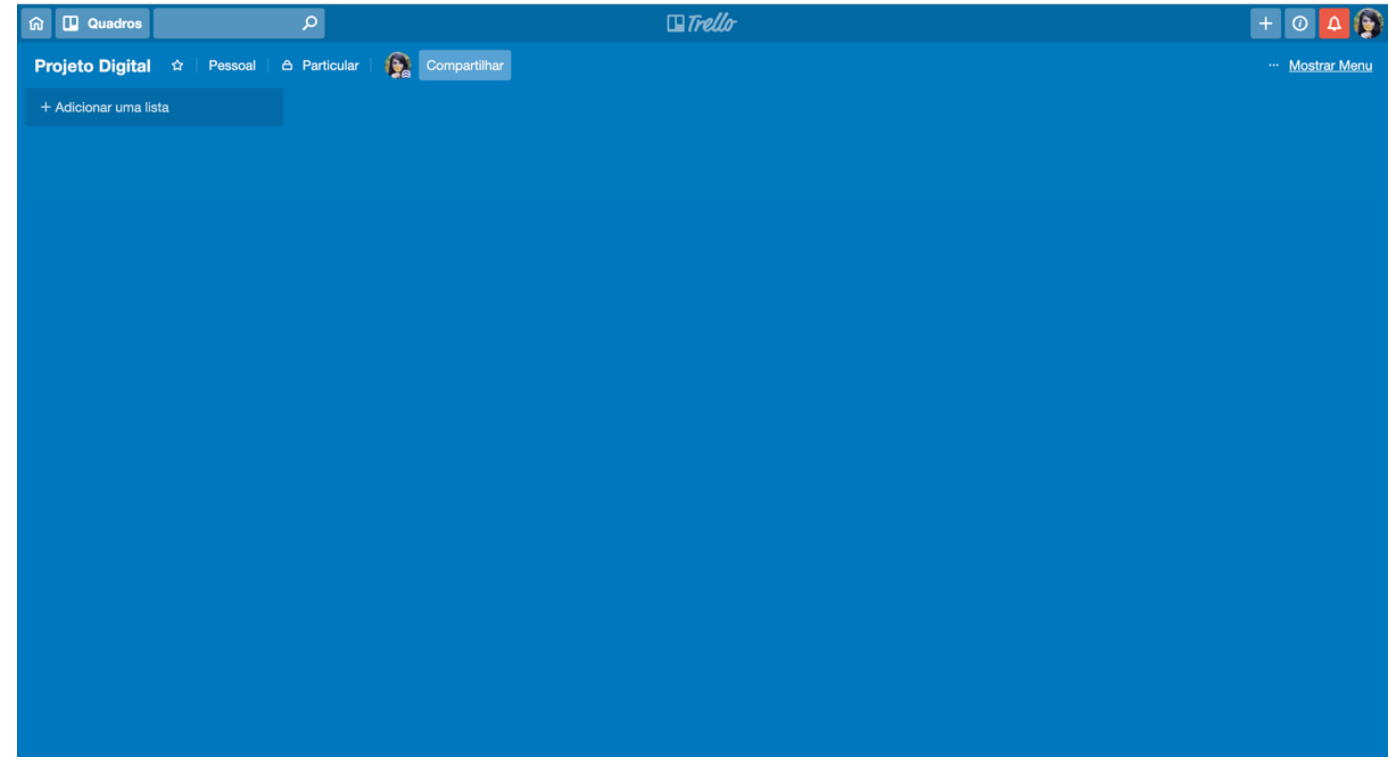

Figura 2 - Exemplo de quadro.

Fonte: Captura de tela realizada por autores. Disponível em: <https://trello.com/>. Acesso em 10 jan. 2019. 
Cada quadro pode ser organizado a partir de uma ou mais listas de tarefas. As listas são agrupamentos verticais compostos de cartões, como pode ser visualizado na Figura 3. Cada lista pode ser nomeada pelo usuário, bem como os cartões: na Figura 4, a lista foi chamada de "Geral" e os cartões "Avisos", "Documentos da disciplina" e "Referências".

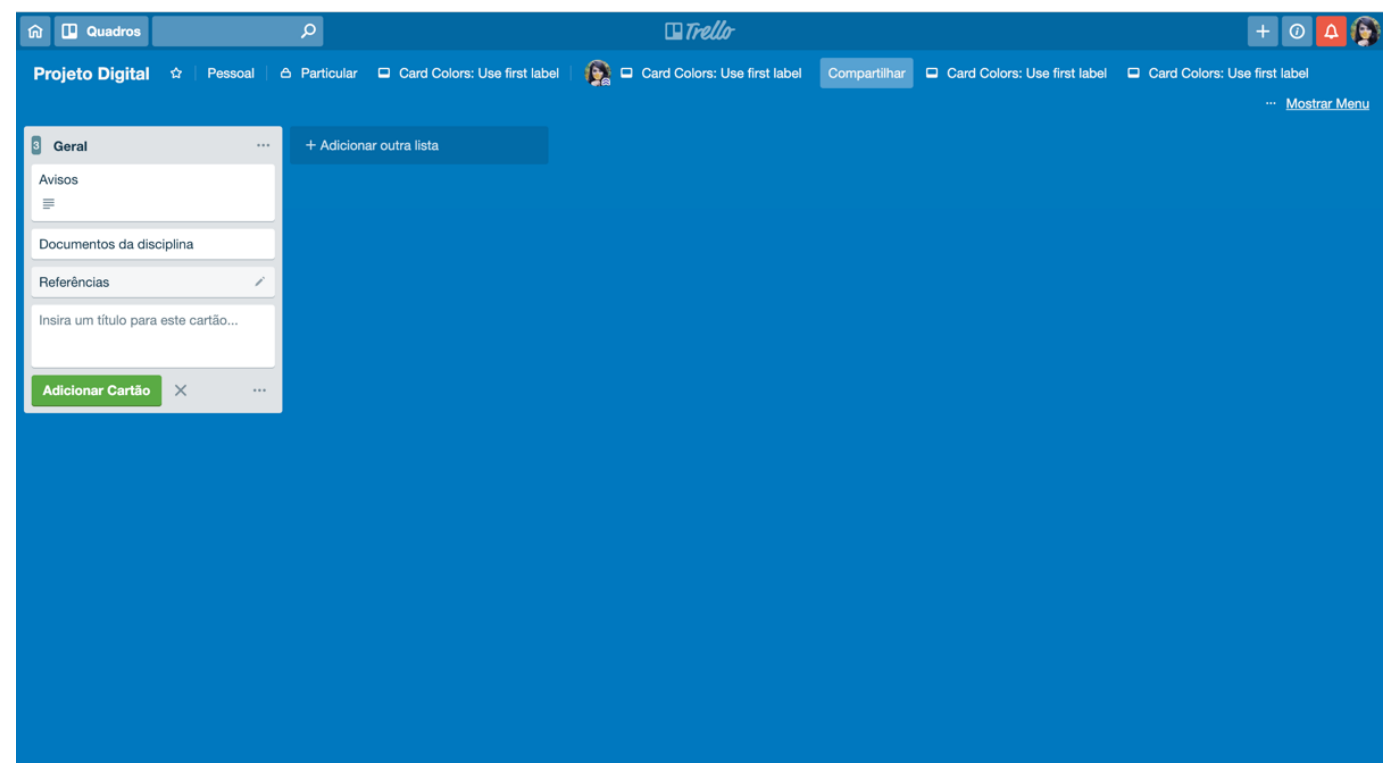

Figura 3 - Exemplo de lista e cartões.

Fonte: Captura de tela realizada por autores. Disponível em: <https://trello.com/>. Acesso em 10 jan. 2019.

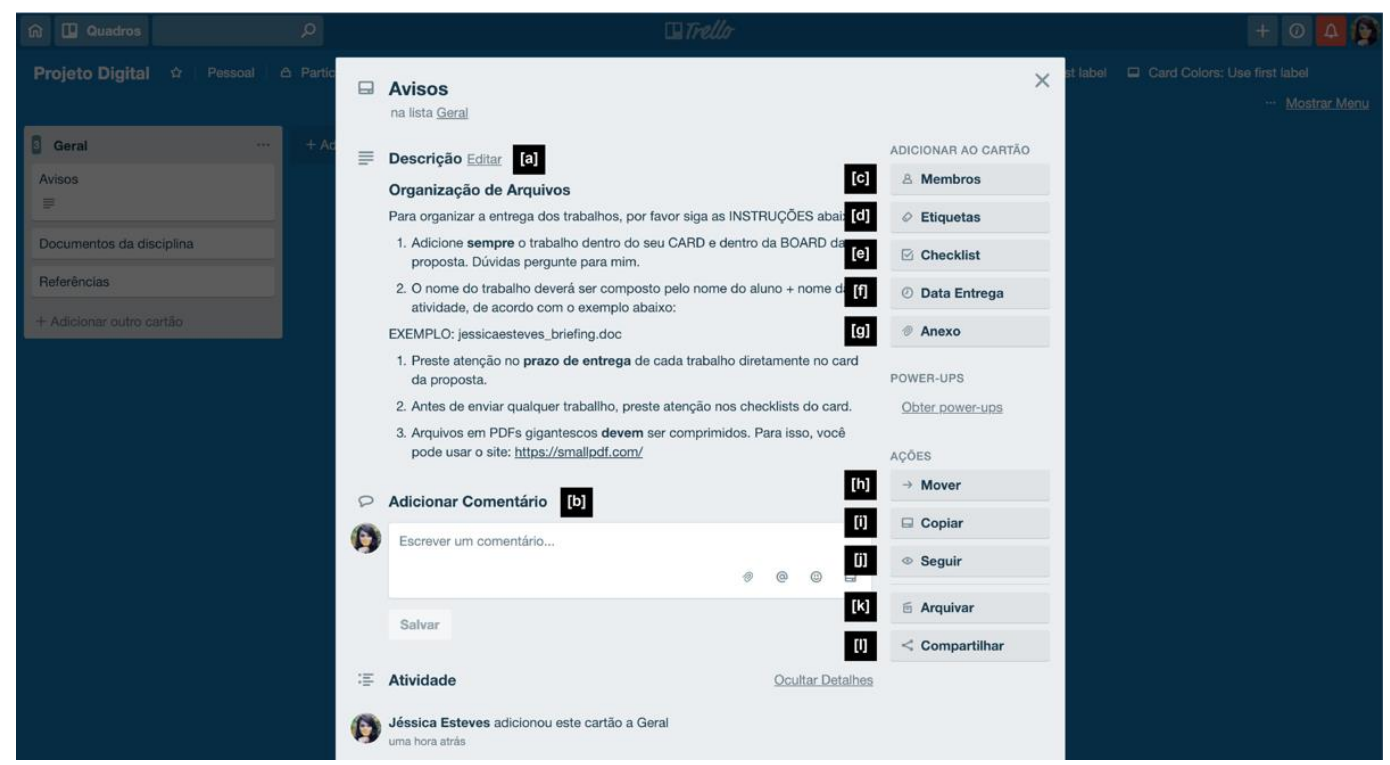

Figura 4 - Exemplo das funcionalidades de um cartão.

Fonte: Captura de tela realizada por autores. Disponível em: <https://trello.com/>. Acesso em 10 jan. 2019. 
RELACult - Revista Latino-Americana de Estudos em Cultura e Sociedade

Revista Latinoamericana de Estudios en Cultura y Sociedad | Latin American Journal of Studies in Culture and Society V. 05, ed. especial, abr., 2019, artigo nº 1337 | claec.org/relacult | e-ISSN: 2525-7870

Ao selecionar um cartão, o usuário é redirecionado para as funcionalidades específicas do mesmo. Cada cartão possui uma série de funcionalidades, como adicionar descrição, membros, etiquetas, checklist, data de entrega, anexo; e ações como conexões, mover, copiar, seguir, arquivar e compartilhar, elencadas na Figura 4. A descrição das funcionalidades identificadas na Figura 4 pode ser observada no Quadro 1.

FUNCIONALIDADES

DESCRIÇÃO

Adicionar

[a] Descrição Possibilita a inclusão de um descritivo sobre o cartão, visível para membros e não-membros do cartão.

[b] Comentários Abaixo da descrição do cartão, é fornecido um campo para que os membros do cartão possam comentar, mencionando uns aos outros se necessário.

[c] Membros Permite incluir membros específicos para determinado cartão, fazendo com que eles recebam notificações sobre os comentários adicionados.

[d] Etiquetas

Cada cartão pode ser organizado através de cores ou nomes por meio de etiquetas, permitindo atribuir significados visuais para o ordenamento de tarefas, como por exemplo: usar verde para entregue, amarelo para em andamento e vermelho para pendente.

[e] Checklist Uma lista de itens a serem completados pode ser adicionada em um cartão, permitindo que usuários possam ir marcando a conclusão conforme fluxo de trabalho.

[f] Data de entrega O usuário pode definir uma data de entrega para determinada atividade/tarefa. Todos os membros do cartão serão notificados por e-mail sobre a proximidade da data do cartão.

[g] Anexo É possível adicionar arquivos a partir do computador, de outro quadro do Trello, de um serviço de armazenamento em nuvem (Google Drive, Dropbox, Box, OneDrive) ou ainda diretamente de um link específico (URL)

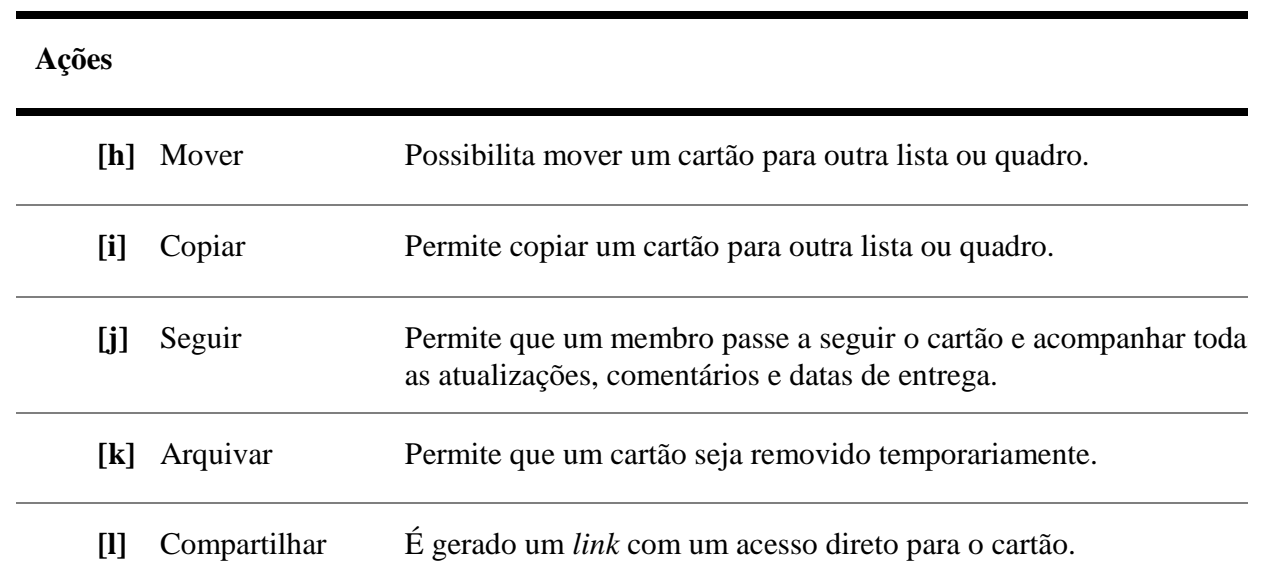

Quadro 1 - Principais funcionalidades do Trello

Fonte: Autores. 
Ao analisar as funcionalidades do Quadro 1, observa-se que as funcionalidades facilitam o acesso de uma equipe sobre determinada tarefa, possibilitando ainda o contato imediato entre os membros através dos comentários; logo, foi compreendido que o Trello poderia ser adequado para a organização de disciplinas projetuais da área de Design, pois: 1) muitas disciplinas envolvem a entrega de arquivos digitais, ou seja, não há a exigência de um trabalho físico impresso entregue ao professor; 2) em disciplinas projetuais, ou seja, que contemplam a realização de um projeto para ser entregue ao fim do semestre, o acompanhamento dos projetos pode se tornar difícil ao professor; e 3) existe uma dificuldade no compartilhamento e visualização de materiais didáticos. Partindo dessas premissas, o Trello foi utilizado como ferramenta de apoio para o ensino da disciplina de Projeto Digital, pertencente ao oitavo semestre do curso técnico integrado em Comunicação Visual.

\section{Metodologia}

Diante das reflexões abordadas, esta pesquisa pode ser classificada como qualitativa, pois trata do envolvimento entre os sujeitos e sua relação com a utilização de uma ferramenta digital para a aprendizagem (SILVA e MENEZES, 2005). Quanto aos procedimentos técnicos, tratou-se de uma pesquisa participante, pois foi desenvolvida a partir da interação entre professores e alunos, sendo estes membros das situações analisadas (GIL, 2002). Esta experiência de ensino foi realizada da seguinte forma: primeiramente, a ferramenta foi organizada pela professora da disciplina antes do início do semestre letivo. Neste processo foram inseridos conteúdos e materiais relevantes para a disciplina, tais como plano de ensino, ementa e apresentações de conteúdo utilizadas nas aulas.

No primeiro dia letivo do semestre, o Trello foi apresentado para os alunos, que foram adicionados à ferramenta e puderam visualizar os materiais já postados. Neste dia, foi enfatizado que todas as entregas de trabalhos deveriam ser realizadas no formato digital inseridas na ferramenta, obedecendo aos prazos de entrega estabelecidos. O Trello foi utilizado como um repositório de conteúdos e compartilhamento de materiais durante todo o semestre. Tratando-se de uma disciplina de projetos, os alunos possuíam entregas semanais que eram postadas e acompanhadas através da ferramenta.

Buscando analisar a percepção dos alunos sobre a utilização da ferramenta digital, ao fim do semestre, foi aplicado um questionário online composto por 5 perguntas abertas e 1 pergunta contendo uma escala de avaliação Likert. Para Bertram (2014), a escala Likert demonstra as preferências e o grau de concordância dos participantes em relação às declarações a serem avaliadas. O questionário online foi respondido por 18 alunos que cursaram a disciplina, 
tendo a abstenção de 2 alunos. O questionário foi respondido de forma anônima, para que os alunos fossem incentivados a responder com sinceridade. A seguir será apresentada a forma de organização da disciplina, inspirada no método Kanban.

\subsection{Organização da Disciplina}

O quadro foi organizado da seguinte forma: primeiramente, foi criada uma lista nomeada Geral, destinada ao armazenamento de informações relativas à disciplina e ao projeto como um todo. Para isso, foram criados 6 cartões, conforme visualização na Figura 5. É possível observar que todos os cartões desta lista são identificados por uma etiqueta roxa, cor que foi atribuída pelos professores para cartões relativos à informações gerais. Outro item a ser observado são os membros de cada cartão da lista Geral, sendo os professores da disciplina. Desta forma, sempre que um aluno comentava com alguma dúvida, os professores da disciplina, membros do cartão, eram diretamente notificados.

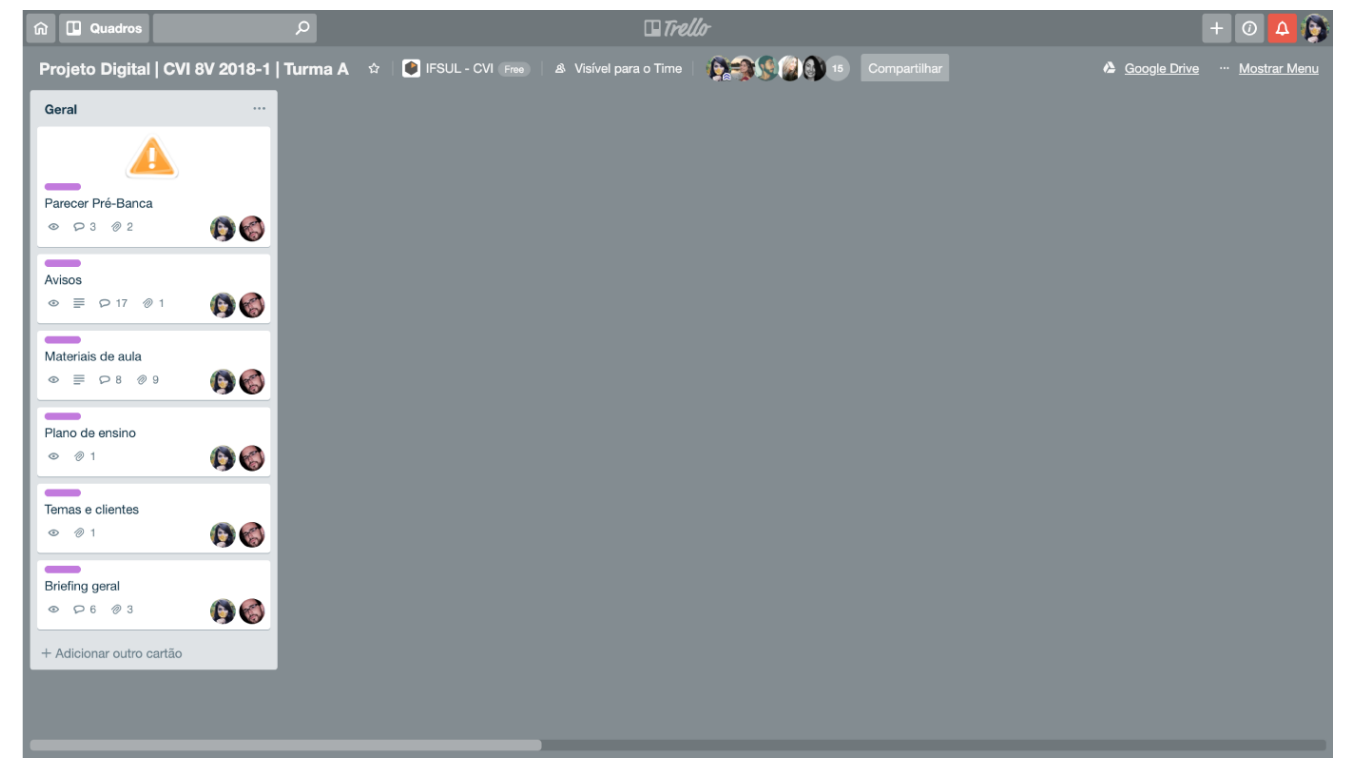

Figura 5 - Quadro da disciplina de Projeto Digital.

Fonte: Captura de tela realizada por autores. Disponível em: <https://trello.com/b/47nIJ3dR/projeto-digital-cvi-8v2018-1-turma-a>. Acesso em 10 jan. 2019.

Após a definição da organização da primeira lista, destinada às informações gerais da disciplina, partiu-se para a definição das listas dos alunos. Dado a quantidade de alunos e de itens entregáveis, optou-se por criar uma lista por aluno; logo, cada lista recebeu o nome do aluno correspondente. Dentro da lista do aluno, foram criados cartões específicos para cada fase do projeto, divido em: briefing, sitemap, wireframes, design visual e protótipo, de acordo com a ementa da disciplina. Cada um desses itens corresponde a uma entrega da disciplina, de modo que dentro de cada cartão é possível ter mais informações sobre a tarefa, como mostra a Figura 
7. Além disso, na Figura 7, é observado a descrição do cartão Wireframe, bem como os arquivos adicionados pela aluna e a data e hora de estrega estipulada.

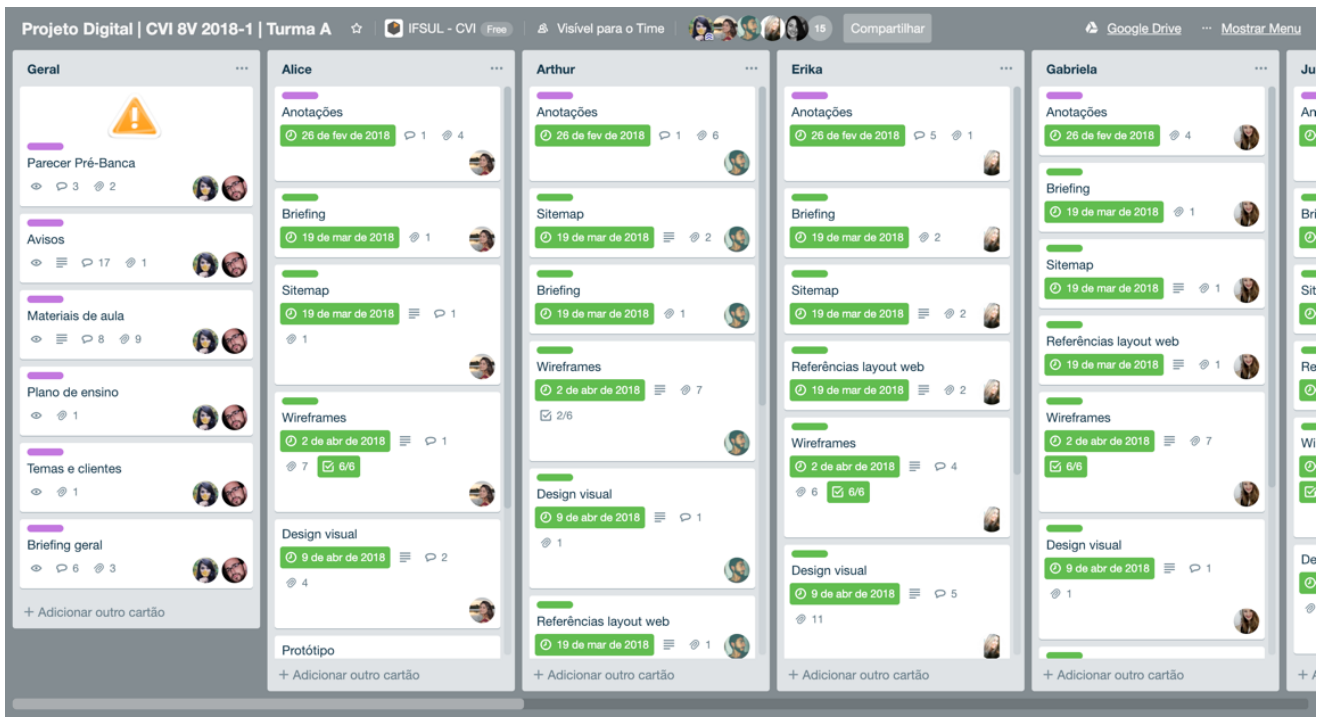

Figura 6 - Visualização de listas e cartões.

Fonte: Captura de tela realizada por autores. Disponível em: <https://trello.com/b/47nIJ3dR/projeto-digital-cvi-8v2018-1-turma-a>. Acesso em 10 jan. 2019.

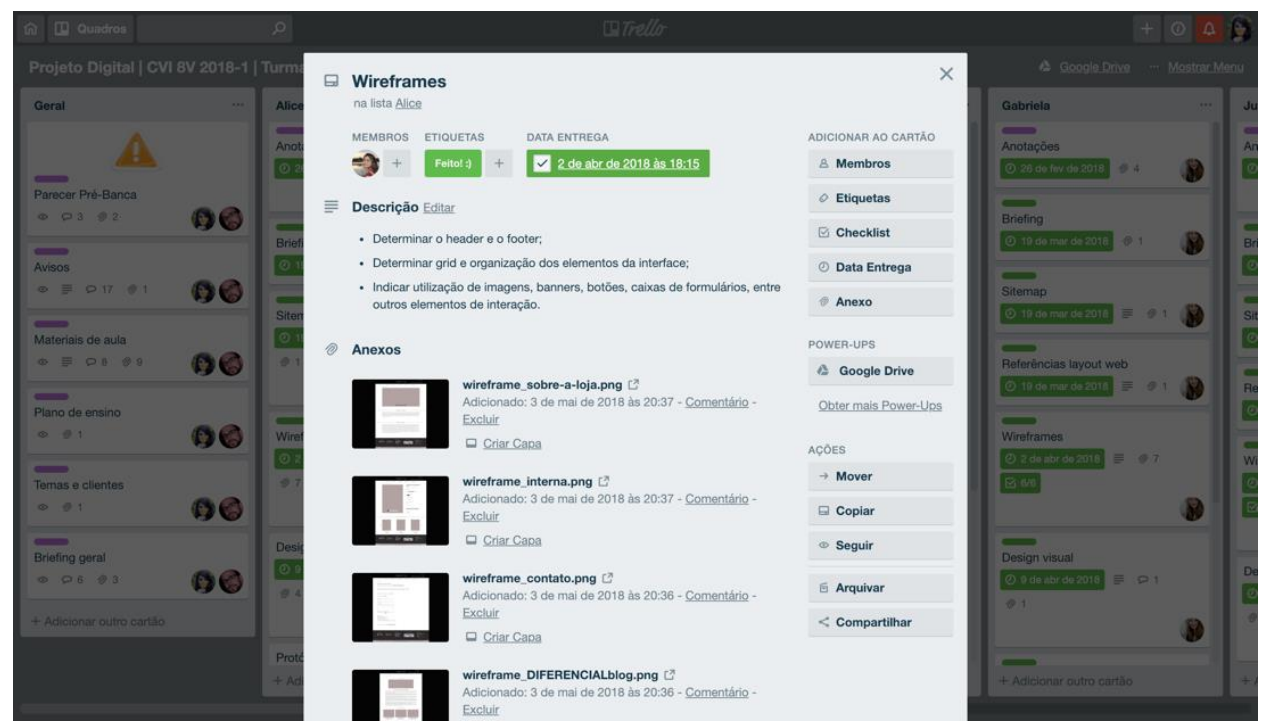

Figura 7 - Visualização de listas e cartões.

Fonte: Captura de tela realizada por autores. Disponível em: <https://trello.com/b/47nIJ3dR/projeto-digital-cvi-8v2018-1-turma-a>. Acesso em 10 jan. 2019.

O quadro da disciplina de Projeto Digital foi utilizado durante todo o primeiro semestre letivo de 2018. A organização das listas do quadro permaneceu a mesma, contudo, novos cartões foram sendo adicionado na medida em que novos assuntos/temas/arquivos eram necessário. O quadro ainda encontra-se disponível para alunos e professores, de modo que estes 
podem visualizar todos os materiais postados e entregues pelos alunos. Ao término do semestre, os alunos foram convidados a preencher um questionário com o objetivo de analisar a experiência pedagógica, itens discutidos na próxima subseção.

\subsection{Resultados e Discussões}

Ao fim do semestre, os alunos foram contatados através do Trello e do WhatsApp para responderem ao questionário. Os alunos foram receptivos quanto ao preenchimento do questionário, possuindo a abstenção de apenas 2 alunos, contanto com 18 alunos participantes. Nesta seção, é feita uma síntese dos principais aspectos evidenciados sobre a experiência de ensino, seguida de uma discussão dos autores sobre os comentários dos alunos.

Ao serem questionados quanto às dificuldades enfrentadas para utilizar a ferramenta, a grande maioria dos alunos relatou que não possuiu nenhuma dificuldade; entretanto, o aluno 5 chamou atenção para a falta de padronização na organização das disciplinas por parte dos professores, o que ocasionou uma dificuldade em entender como utilizar a ferramenta. É conveniente ressaltar que outros professores do curso Técnico em Comunicação Visual utilizam a ferramenta em suas disciplinas, mas a presente pesquisa trata do uso específico do Trello na disciplina de Projeto Digital; contudo, o comentário do estudante mostrou-se pertinente para uma discussão maior sobre padronização da organização do Trello. $\mathrm{O}$ aluno 12 diverge do comentário do aluno anterior, afirmando que:

$\mathrm{Na}$ experiência que tive com o Trello cada professor organizava os times de uma maneira diferente. Na época não via tanta dificuldade, mas hoje em dia gosto de utilizar trabalhos de ex-colegas como exemplo em trabalhos da faculdade e tenho dificuldade para encontrar os quadros.

A partir do comentário, é observado que o aluno, mesmo após ter se formado, segue utilizando os materiais do Trello como referência para os trabalhos da faculdade, mostrando o potencial pedagógico da ferramenta, por se tratar de um ambiente digital e de livre acesso.

Ainda sobre dificuldades enfrentadas para utilizar a ferramenta, o aluno 15 alegou que não possuía dificuldades, mas "gostaria de saber mais o que o Trello oferece". Esta afirmação enfatiza a necessidade de uma maior capacitação dos alunos e professores sobre as potencialidades pedagógicas e tecnológicas da ferramenta, que não foram exploradas com profundidade durante a experiência de ensino. Outro aspecto negativo evidenciado pelo aluno 8 é que "uma das únicas coisas que acho ruim é que para fazer upload ele não suporta arquivos muito pesados", opinião esta que corrobora para a necessidade de uma maior capacitação dos alunos para a utilização da ferramenta, pois, conforme evidenciado no Quadro 1, é possível 
fazer o upload de arquivos utilizando um serviço de armazenamento em nuvem (Google Drive, Dropbox, Box, OneDrive), não tendo limite de peso de arquivo.

A fim de propor uma reflexão pessoal sobre o uso da ferramenta no seu cotidiano, foi pedido que os alunos comentassem sobre suas experiências utilizando o Trello no decorrer do semestre. A aluna 3 comentou sobre sua relutância inicial com a ferramenta e também sobre a potencialidade pedagógica para o ensino de disciplinas projetuais:

Tive muita relutância em utilizar o Trello no início porque era algo a que eu não estava acostumada e rolava aquele confronto com o novo. Mas principalmente durante o projeto final acredito que tenha sido de extrema importância tanto para organização pessoal quanto da turma, como para o feedback que na maioria das vezes não dava tempo de ser feito em aula. Mas agora que me acostumei com ele uso tanto no trabalho quanto para coisas pessoais, até lista de supermercado já fiz no Trello.

O comentário da estudante traz à tona um aspecto interessante no uso de tecnologia para o ensino de estudantes nativos digitais: muitos deles podem possuir uma postura conservadora quanto à utilização de ferramentas digitais desconhecidas, ainda que estejam imersos diariamente no ambiente digital. Esta observação parte dos professores pesquisadores deste artigo, que ao acompanhar a turma em mais de um semestre letivo, presenciaram o receio de alguns alunos ao utilizarem a ferramenta.

A aluna 9 relata que dado sua primeira experiência com a ferramenta no curso, incentivou seus colegas do trabalho e da faculdade a também utilizarem a plataforma.

Depois que conheci o Trello no ambiente do curso, incentivei meus colegas do trabalho e da faculdade a também utilizarem a plataforma e recebi um feedback muito positivo pois todos acharam a ferramenta mais apropriada para os projetos do que o Google Drive, Dropbox e OneDrive, plataformas que utilizavam anteriormente.

Quando questionados se sabiam utilizar as funcionalidades do Trello, os alunos alegavam que sim; no entanto, ao observar a forma como realizavam o upload de arquivo e alterações nos cartões, observou-se que alguns não sabiam de fato como realizar essas tarefas. Este aspecto evidencia que a ferramenta não é tão intuitiva e simples, possuindo problemas de interface do usuário. O comentário da aluna 17 faz referência à inconsistências observadas na interface do Trello:

[...] não me agrada a forma como o cartão abre na tela, pois os espaços que "sobram" dos lados poderiam ser melhor utilizados para distribuição do conteúdo interno, tipo checklists e anexos, de modo que eles ficassem um do lado do outro e a gente não precisasse scrollar tanto a tela. Além disso, acho que as opções que tipo membros, etiquetas, etc, podiam estar posicionadas horizontalmente e no topo e nela poderiam ser aplicadas cores pra ser mais fácil o discernimento dessas opções. Tudo isso acho que contribuiria pra experiência e facilidade de navegação, ao meu ver.

Por fim, a última pergunta do questionário pedia que os alunos avaliassem 5 aspectos da ferramenta (interface gráfica, facilidade de navegação, notificações, download de arquivos, 
upload de arquivos), em uma escala de 1 a 5, sendo: 1 - péssimo, 2 - ruim, 3 - regular, 4 bom, 5 - ótimo. Os resultados podem ser visualizados na Figura 8, apontando que existem vários itens a serem melhorados, como por exemplo o upload de arquivos e a interface gráfica.

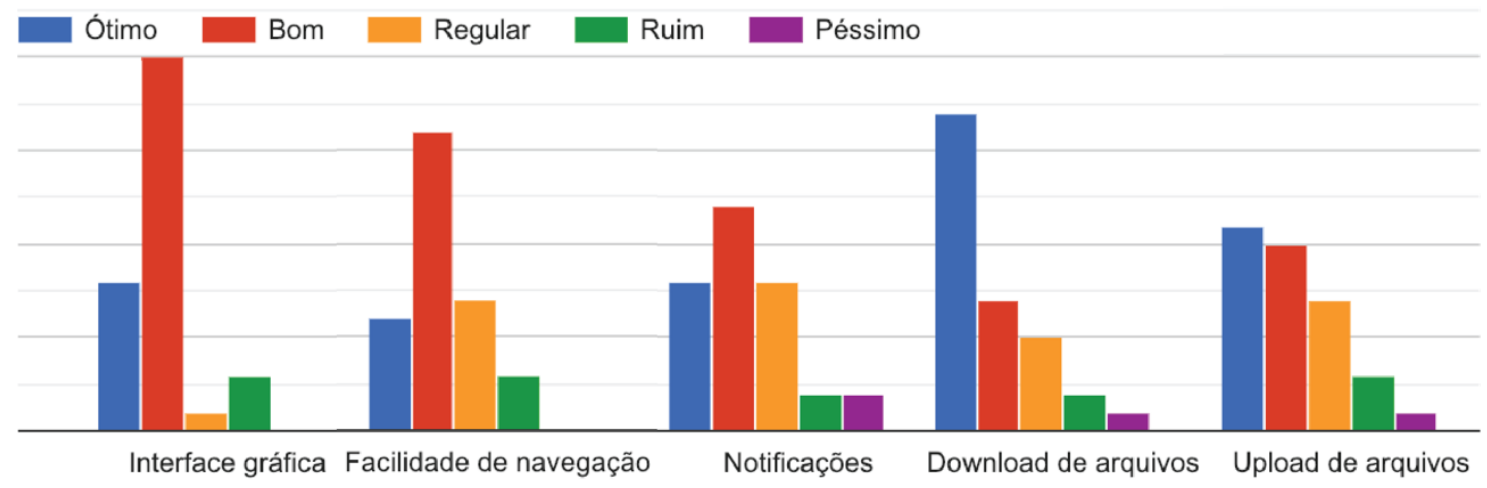

Figura 8 - Avaliação do Trello.

Fonte: Autores.

Com a análise das respostas dos questionários, foi possível perceber aspectos positivos e negativos na utilização do Trello como ferramenta para mediação pedagógica no ambiente digital. Foi observado que uma das maiores dificuldades dos alunos é devido a inconsistências presentes na interface gráfica e o desconhecimento de funcionalidades da ferramenta, o que aponta para uma necessidade de capacitação para os alunos utilizarem a ferramenta. Outro item que deve ser destacado é a utilização do Trello pelos alunos em outros meios, como na organização pessoal ou no mundo do trabalho, enfatizando que o uso da ferramenta não ficou restrita ao uso no ambiente escolar.

\section{Conclusões}

Ao promover esta experiência de ensino com os alunos do oitavo semestre do curso Técnico em Comunicação Visual do IFSul procurou-se refletir sobre aspectos positivos e negativos da utilização de uma ferramenta digital para a mediação do processo de ensino e aprendizagem da disciplina de Projeto Digital. Os resultados da experiência apontaram que o uso do Trello foi positivo, contribuindo para a organização dos materiais, contato com professores e entregas durante o semestre. Para os docentes, o uso da ferramenta tornou o acompanhamento das atividades mais fácil, permitindo que estes pudessem visualizar o desenvolvimento do trabalho através das postagens dos alunos.

A partir dos relatos dos alunos, foi percebido que o uso do Trello forneceu uma maior transparência no processo de ensino e aprendizagem, permitindo que os estudantes observassem com clareza os prazos de entrega e os materiais de aula. Contudo, inconsistências presentes na 
interface gráfica da ferramenta foram elencadas pelos alunos, itens que dificultaram o entendimento das tarefas, o que pode ter impactado negativamente os processos de ensino e aprendizagem. Ao fim da análise das respostas do questionário, é evidenciada a necessidade em se construir uma proposta didático-pedagógica para auxiliar professores e docentes na criação de quadros e listas no Trello.

Dado o contexto, acredita-se que este trabalho foi ao encontro de seu objetivo principal, compartilhar uma experiência de ensino e aprendizagem a partir do uso de uma ferramenta digital para o ensino de disciplinas projetuais em Design, através de um relato de experiência.

Por fim, é esperado que este trabalho possibilite maiores discussões e experiências pedagógicas envolvendo o uso do Trello em sala de aula, contribuindo para a expansão de discussões aqui iniciadas. De forma geral, acredita-se que este artigo possa servir de incentivo para que outros docentes experimentem utilizar ferramentas digitais em aula.

\section{Referências}

BERTRAM, D. Likert Sales... are the meaning of Life. CPSC 681 - Topic Report, 2014. Disponível em: <http://poincare.matf.bg.ac.rs/ kristina/topic-dane-likert.pdf>. Acesso em: 10 jan. 2018.

GIL, A. C. Métodos e técnicas de pesquisa social. 6. Ed. São Paulo: Editora Atlas SA, 2008.

IBGE. Pesquisa nacional por amostra de domicílios: síntese de indicadores. Coordenação de Trabalho e Rendimento. Rio de Janeiro: IBGE, 2016. 108p. Disponível em: <https://goo.gl/3i9GtE >. Acesso em: 10 jan. 2018.

LEMOS, A. Cibercultura: tecnologia e vida social na cultura contemporânea. 6. ed. Porto Alegre: Sulina, 2013.

LÉVY, P. Cibercultura. 5. ed. São Paulo: Editora 34 LTDA, 2005.

LÉVY, P. Uma perspectiva vitalista sobre a cibercultura. In: LEMOS, André. Cibercultura tecnologia e vida social na cultura contemporânea. Porto Alegre: Sulina, 2002.

SILVA, E. L.; MENEZES, E. M. Metodologia da Pesquisa e Elaboração de Dissertação. 4.ed. Florianópolis: UFSC, 2005. 138p.

TÔNUS M. Interação do Processo de Aprendizagem em Comunicação Social. In: PRIMO, A. Comunicação e Interações. Livro da COMPÓS. Porto Alegre: Sulina, 2008. 